11

\title{
Роль модельных представлений в описании кинетики люминесценции гибридных нитевидных нанокристаллов
}

\author{
(C) А.С. Кулагина ${ }^{1}$, А.И. Хребтов ${ }^{1}$, Р.Р. Резник ${ }^{2}$, Е.В. Убыйвовк ${ }^{2,3}$, А.П. Литвин ${ }^{2}$, И.Д. Скурлов ${ }^{2}$, \\ Г.Э. Цырлин ${ }^{1,2,4,5}$, Е.Н. Бодунов ${ }^{6}$, В.В. Данилов ${ }^{6}$ \\ ${ }^{1}$ СПбАУ РАН, Академический университет, \\ 194021 Санкт-Петербург, Россия \\ ${ }^{2}$ Университет ИТМО, \\ 197101 Санкт-Петербург, Россия \\ ${ }^{3}$ Санкт-Петербургский государственный университет, \\ 199034 Санкт-Петербург, Россия \\ ${ }^{4}$ Институт аналитического приборостроения РАН, \\ 190103 Санкт-Петербург, Россия \\ ${ }^{5}$ Санкт-Петербургский государственный электротехнический университет „ЛЭТИ“ им. В.И. Ульянова (Ленина), \\ 197376 Санкт-Петербург, Россия \\ ${ }^{6}$ Петербургский государственный университет путей сообщения Императора Александра I, \\ 191031 Санкт-Петербург, Россия \\ e-mail: a.s.panfutova@gmail.com
}

Поступила в редакцию 09.09.2019 г.

В окончательной редакции 09.09.2019 г.

Принята к публикации 26.09.2019 г.

\begin{abstract}
Исследована фотодинамика люминесценции массива нитевидных нанокристаллов InP/InAsP/InP, сформированных методом молекулярно-пучковой эпитаксии на подложке $\mathrm{Si}(\mathrm{III})$. На основе сопоставления нескольких кинетических моделей проведён анализ экспериментальных данных, полученных при возбуждении лазерным излучением $633 \mathrm{~nm}$ при комнатной температуре. Показано, что кинетика затухания люминесценции нановставки InAsP лучше всего описывается в рамках модели контактного тушения. Оценена полная длительность распада возбужденного состояния (радиационное время жизни) нановставки InAsP $\tau \sim 40 \mathrm{~ns}$. Высказаны предположения о причинах необычно большой длительности переноса возбуждения от InP.
\end{abstract}

Ключевые слова: гибридные нитевидные нанокристаллы, кинетика люминесценции, фотодинамика.

DOI: $10.21883 /$ OS.2020.01.48848.262-19

\section{Введение}

В последнее время полупроводниковые нитевидные нанокристаллы (ННК) благодаря своим уникальным свойствам находят широкое практическое применение в области фотовольтаики, фотодетекции, оптоэлектроники, медицины ит.д. [1-4]. Особый интерес представляет возможность создания гетероструктур типа нановставка (или квантовая точка) в теле ННК с большей шириной запрещенной зоны, что позволяет расширять диапазон излучения ННК, получать источники одиночных фотонов, формировать направленные источники излучения [5-8]. Однако полупроводниковые нанокристаллы часто характеризуются сложной динамикой возбужденного состояния. Отсюда необходимость понимания физических принципов, регулирующих фотодинамику люминесценции в наноструктурах. С этих позиций максимально информативным является использование спектрокинетических методов [9-12]. Однако отсутствие устойчивого формализма часто приводит к неоднозначности в трактовке экспериментальных результатов. В этом случае принципиальное значение приобретает качество обработки экспериментальных зависимостей кинетики люминесценции [13-17]. Целью исследования настоящей работы являлось изучение кинетики фотолюминесценции (ФЛ) гибридной полупроводниковой наноструктуры, представляющей собой массив НHК InP/InAsP/InP, сформированных методом молекулярно-пучковой эпитаксии на подложке $\mathrm{Si}(\mathrm{III})$, путём аппроксимации экспериментальных кинетических зависимостей несколькими математическими моделями. Сопоставление полученных результатов позволило получить комплексное описание фотодинамики люминесценции данной структуры.

\section{Экспериментальные методы}

ННК были синтезированы методом молекулярнопучковой эпитаксии на установке Compact21 фирмы Riber. Средняя высота ННК InP составляла $4 \mu \mathrm{m}$, a диаметр оказался неоднородным по высоте и составил $100 \mathrm{~nm}$ у основания и $30 \mathrm{~nm}$ на вершине ННК при их поверхностной плотности $3 \cdot 10^{8} \mathrm{~cm}^{-2}$. Размеры нановставки (НB) InAsP (содержание As $~ 40 \%$ ) составили $60 \mathrm{~nm}$ в длину и $5 \mathrm{~nm}$ в ширину (рис. 1,a) (глубина залегания НВ в теле ННК составила $\sim 10 \mathrm{~nm})$. 

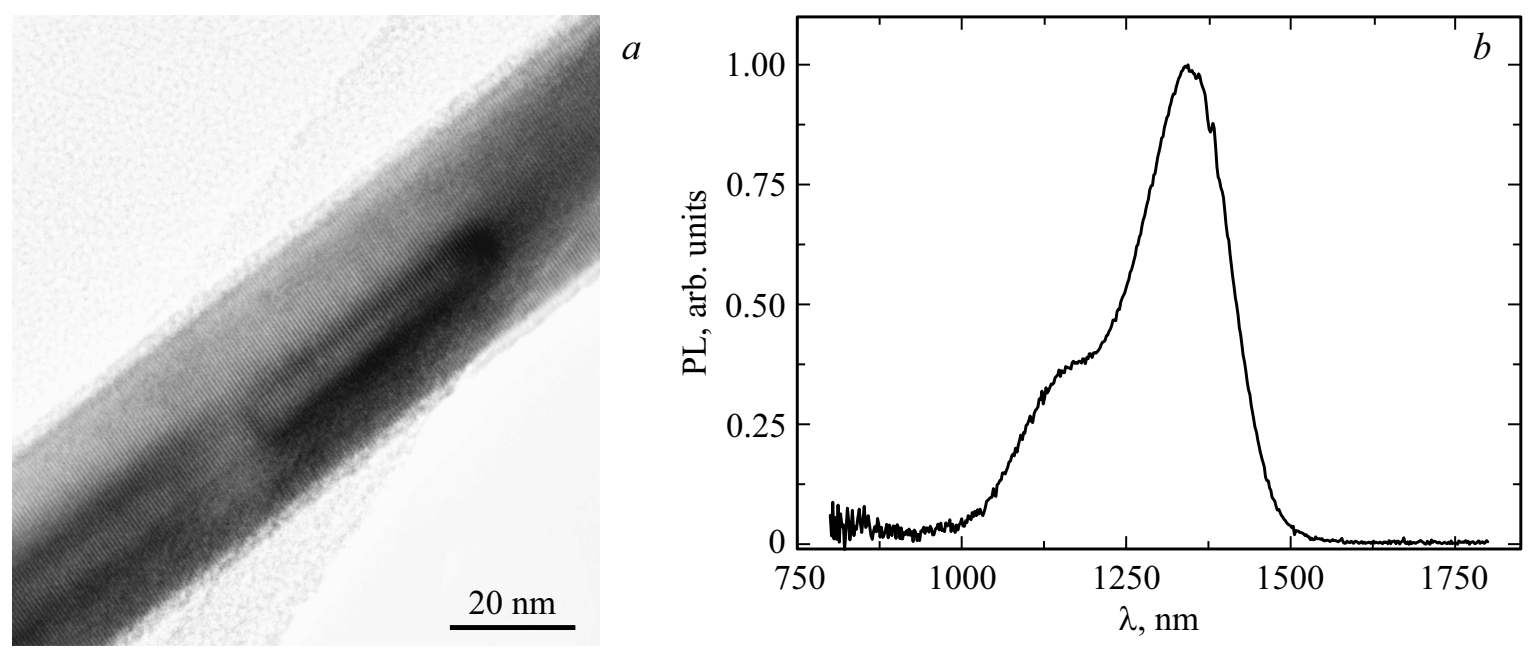

Pис. 1. (а) ПЭМ-изображение участка ННК InAs с HB InAsP, (b) спектр ФЛ массива ННК InP c HB InAsP.

На рис. 1, $a$ виден радиальный след того же материала на некотором расстоянии от HB InAsP. Это радиальная квантовая яма (КЯ) со средним содержанием 15-25\% по мышьяку, образованная при осаждении тонкого слоя InAsP на поверхность InP во время формирования НB.

На рис. 1, $b$ приведён спектр люминесценции выращенной структуры. Для возбуждения люминесценции использовался непрерывно излучающий лазер с длиной волны $633 \mathrm{~nm}$ при мощности излучения около $6 \mathrm{~mW}$. Вторичное излучение собиралось по стандартной схеме под углом $90^{\circ}$, возбуждающее излучение отсекалось светофильтром КС19 (длина волны отсечки $680 \mathrm{~nm}$ ). Полученные спектры нормировались на чувствительность детектора.

Спектры и кинетика ФЛ измерялись от массива ННК с площади около $5 \mu \mathrm{m}^{2}$ и регистрировались в ближнем ИК диапазоне с помощью InGaAs-фотодиода (Hamamatsu).

При исследовании кинетики люминесценции в качестве источника возбуждения использовался импульсный лазер с длиной волны $633 \mathrm{~nm}$ (частота следования $\sim 2.5 \mathrm{MHz}$, энергия в импульсе $\sim 6 \mathrm{~nJ}$, длительность импульса $<100 \mathrm{ps})$. Длина волны регистрации кинетики люминесценции НВ составляла $1350 \mathrm{~nm}$. Все измерения проводились при комнатной температуре $T=293 \mathrm{~K}$.

\section{Обсуждение результатов}

Как видно из рис. $1, b$, в спектрах люминесценции массивов НHK InAsP/InP наблюдаются интенсивные полосы в области $1.0-1.5 \mu \mathrm{m}$. Полоса люминесценции в области $1.25-1.5 \mu \mathrm{m}$ соответствует свечению HB InAsP. Коротковолновую полосу $1.0-1.2 \mu \mathrm{m}$ мы относим к свечению радиальной КЯ. При фиксированной геометрии возбуждения наблюдающееся перераспределение интенсивностей полос связано с разницей спектров поглощения НВ и КЯ.
Затухание люминесценции нанокристаллов при комнатной температуре часто носит неэкспоненциальный характер (см., например, [18-20]), который записывается в виде суммы нескольких экспонент:

$$
I_{\text {norm }}=\sum_{i} A_{i} e^{-t / \tau_{i}}
$$

Здесь $I_{\text {norm }}$ - нормированная на единицу в начальный момент времени интенсивность затухания люминесценции; условие, накладываемое на амплитуды, $\sum A_{i}=1$. Такой подход предполагает существование либо нескольких безызлучательно связанных метастабильных состояний, либо нескольких групп нанокристаллов с различной морфологией и разными временами затухания люминесценции. Относительная доля этих состояний (или групп) в суммарной кинетике затухания характеризуется коэффициентами $A_{i}$ при экспонентах. (Похожая ситуация наблюдается при триплет-триплетной аннигиляции $[21,22]$.)

Из рис. 2 видно, что кинетики затухания люминесценции HB InAsP при комнатной и азотной температурах очень близки. Поэтому дальнейший анализ мы проводим только для случая 293 К. Наилучшая аппроксимация экспериментальных данных достигается при использовании функции затухания, состоящей из суммы двух экспонент:

$$
I_{\text {norm }}=A_{1} e^{-t / t_{1}}+A_{2} e^{-t / t_{2}},
$$

где $A_{1}+A_{2}=1 . \mathrm{B}$ табл. 1 представлены параметры этой аппроксимации.

Приведенный в табл. 1 диапазон времён затухания определён из серии одинаковых кинетических экспериментов и обусловлен геометрическими и морфологическими различиями ННК в массиве. Мы наблюдаем, что люминесценция с основного возбужденного состояния НВ (спектрально она неразличима) распадается на две компоненты с временами затухания порядка 10 и $45 \mathrm{~ns}$. При этом амплитуда первой компоненты $\left(A_{1}\right)$ в 


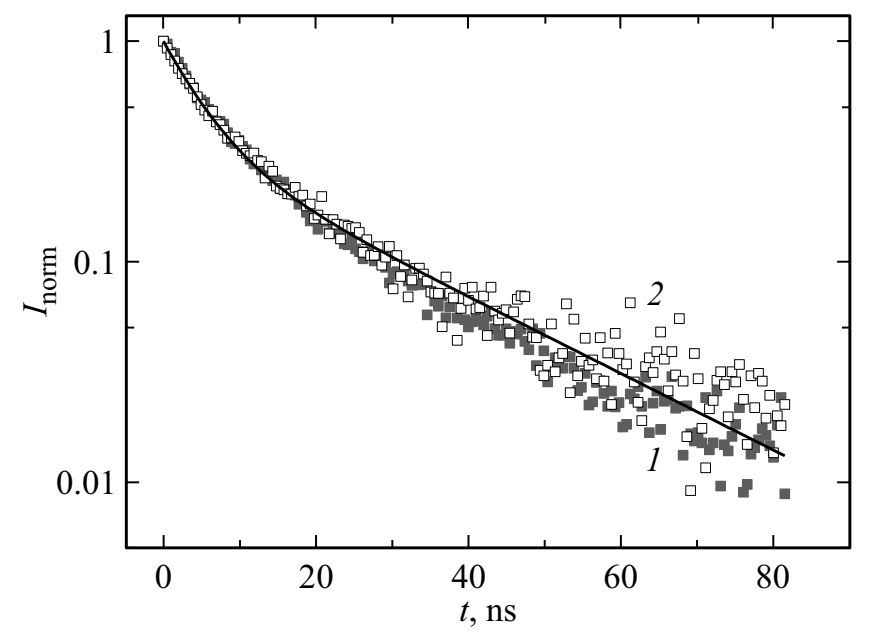

Рис. 2. Нормированная экспериментальная кинетика люминесценции НВ (точки), измеренная при 77 (1) и при 293 К (2), и аппроксимация функцией (1) (сплошная кривая).

Таблица 1. Времена жизни люминесценции НВ и их амплитуды для модели (1)

\begin{tabular}{c|c}
\hline Параметры модели (1) & Значения \\
\hline$A_{1}$ & 0.66 \\
$t_{1}, \mathrm{~ns}$ & $5-8$ \\
$A_{2}$ & 0.34 \\
$t_{2}, \mathrm{~ns}$ & $25-44$
\end{tabular}

2 раза больше амплитуды второй $\left(A_{2}\right)$. Мы полагаем, что люминесценция НВ (помимо прямого возбуждения) имеет дополнительный канал подкачки возбужденного состояния, например с ловушек или за счёт переноса (в той или иной форме) возбуждения от КЯ и массива InP.

Для того чтобы определить влияние КЯ на кинетику НB, нами была проведена серия экспериментов по измерению кинетики люминесценции КЯ. Кинетика КЯ регистрировалась на длине волны $1145 \mathrm{~nm}$ и наилучшим образом описывалась одной экспонентой. Обнаружено, что время жизни люминесценции КЯ не превышало $10 \mathrm{~ns}$, что практически совпадает со временем свечения короткой компоненты НВ. Поскольку природа излучающих центров КЯ и НВ практически идентична, времена жизни их излучающих состояний должны быть близки. Сравнение кинетик затухания люминесценции НВ и КЯ позволило нам отождествить короткую компоненту люминесценции НВ (c $t_{1}$ порядка $10 \mathrm{~ns})$ с длительностью распада возбужденного состояния HB InAsP. Отсюда с учётом определённого по зависимости амплитуды люминесценции от мощности возбуждения (см., например, [23]) квантового выхода для нашей системы $(\sim 0.4-0.5[8])$ мы можем оценить естественное время жизни возбужденного состояния $\mathrm{HB}$ $\sim 10-20 \mathrm{~ns}$.
Длительная компонента свечения имеет сложную природу. С одной стороны, она может определяться возбужденным состоянием InP, которое заселяет излучающее состояние НВ путём излучательного и безызлучательного переноса возбуждения. Например, авторы [24] показывают наличие зависимости времени жизни НВ InAsP от диаметра $(d)$ HНК InP и вводят отношение $d / \lambda$, где $\lambda$ - длина волны люминесценции НВ. Для наших образцов значение этого отношения 0.022, и, согласно приведённой в [24] экспериментальной зависимости, радиационное время жизни должно превышать 25 ns. Однако фотодинамика возбуждения InAsP через этот канал, хотя частично и объясняется авторами [24], требует дальнейшего уточнения. С другой стороны, увеличение длительности излучательной рекомбинации InAsP в НHK InP может быть связано с пространственным разделением носителей заряда в НВ вследствие возникновения гетерограницы 2-го рода между НВ InAsP и объёмом HНK InP $[25,26]$. Подобный эффект наблюдался в НHК на основе $\mathrm{GaAs} / \mathrm{AlGaAs}$ и был объяснён возникновением в ННК областей с разным типом кристаллической решётки [27].

В работах $[14,15]$ при интерпретации кинетики затухания люминесценции коллоидных растворов квантовых точек $\mathrm{CdSe} / \mathrm{ZnS}$ было предложено использовать растянутую экспоненту (stretched exponential function) [20]:

$$
I_{\text {norm }}(t)=\exp \left[-\frac{t}{\tau}-a\left(\frac{t}{\tau}\right)^{\beta}\right]
$$

Здесь $\tau-$ время жизни возбужденного состояния люминесцирующих квантовых точек, значения параметра $\beta$ лежат в интервале $0<\beta \leq 1$ и зависят от механизма тушения люминесценции (диполь-дипольный, дипольквадрупольный или квадрупроль-квадрупольный), $a$ константа, зависящая от концентрации тушащих молекул. Подгоночными параметрами в (2) являются три коэффициента: $\tau, a$ и $\beta$. Отметим, что время $\tau$ можно определить из независимых экспериментов. Тогда число подгоночных параметров сокращается до двух. Принципиально важно, что в случае люминесценции такой подход позволяет отталкиваться от принципа неизменности естественного времени жизни единственного излучающего состояния [28]. Естественное время жизни не зависит от температуры (в отличие от радиационного), что также определило ограничение анализа кинетики люминесценции условиями комнатной температуры. Если параметр $\tau$ фиксировать, то значения $\beta$ в кинетике можно связать с процессами тушения люминесценции различной природы. Чаще всего функция (2) используется для описании кинетики затухания люминесценции при фёрстеровском резонансном переносе энергии (Forster Resonant Energy Transfer, FRET) от молекул-доноров энергии на молекулы-акцепторы. Далее мы использовали эту функцию для описания кинетики люминесценции исследуемых образцов. 


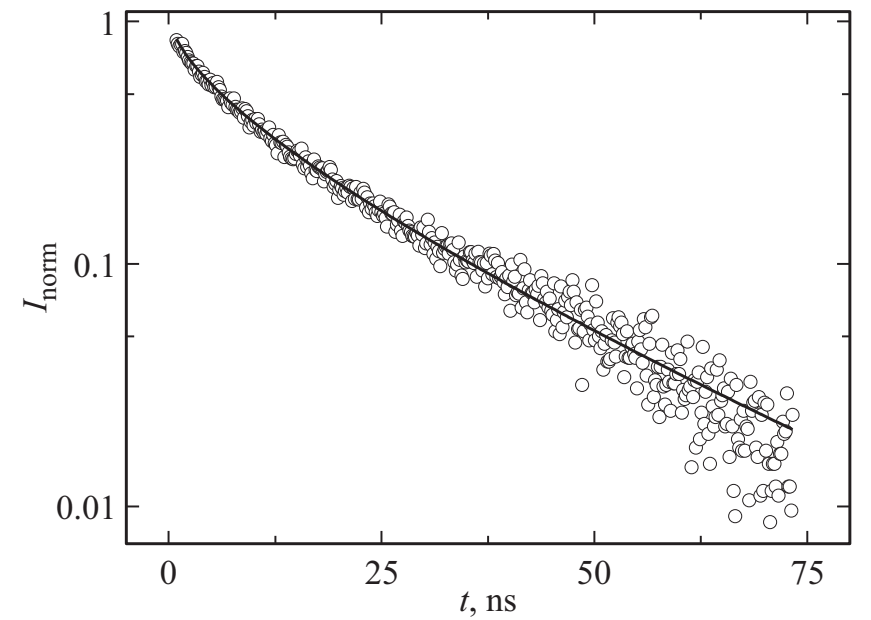

Рис. 3. Нормированная экспериментальная кинетика люминесценции НВ (точки) и аппроксимация функцией (2) (сплошная кривая) при значениях параметров $\tau=45 \mathrm{~ns}, \beta=0.5$, $a=1.8$.

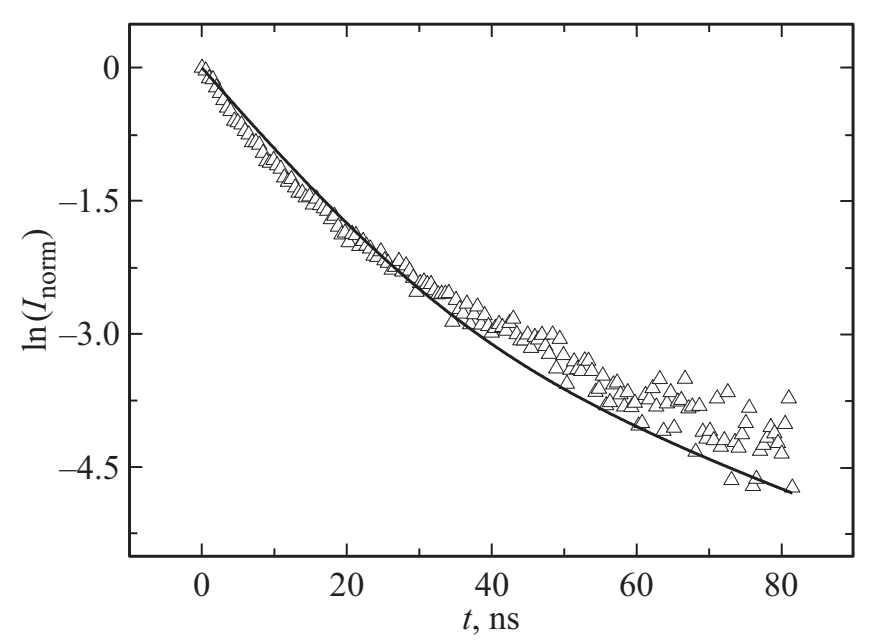

Рис. 4. Нормированная экспериментальная кинетика люминесценции НВ (точки), представленная в логарифмическом виде, и аппроксимация функцией (3) (сплошная кривая).

Из полученных результатов следует (рис. 3), что время радиационного распада излучательного состояния составляет $\sim 45 \mathrm{~ns}$, что приблизительно совпадает с суммарной длительностью компонент свечения из табл. 1. Кроме того, удовлетворительное описание экспериментальных результатов с помощью этой модели при значении $\beta=0.5$ показывает, что доминирующим механизмом тушения люминесценции НВ является дипольдипольный перенос энергии на тушители $[15,29]$.

Как обсуждалось выше, при облучении светом возбуждается не только НВ, но и КЯ. Поскольку спектр люминесценции КЯ сдвинут в коротковолновую область относительно спектра люминесценции НВ, кроме очевидного излучательного переноса возможен безызлучательный перенос энергии (FRET) с КЯ на НB.
Таблица 2. Времена жизни люминесценции НВ и КЯ по модели (3)

\begin{tabular}{c|c}
\hline Параметры модели (3) & Значения \\
\hline$\tau_{\mathrm{QW}}, \mathrm{ns}$ & 100 \\
$\tau, \mathrm{ns}$ & 10 \\
$k, \mathrm{~ns}^{-1}$ & 0.02 \\
$B$ & 0.325
\end{tabular}

Примечание. * Параметр $\tau$ был фиксирован.

Следовательно, возбуждение НВ может осуществляться как прямым возбуждением, так и в результате FRET (сенсибилизированная люминесценция). Решение соответствующих кинетических уравнений (трехуровневая система - возбужденное состояние КЯ, возбужденное и основное состояния НВ) даёт следующую формулу для кинетики затухания люминесценции НB с учётом дополнительного возбуждения через КЯ:

$$
\begin{aligned}
I_{\text {norm }}(t)= & e^{-t / \tau}\left[1+\frac{k B}{1 / \tau_{\mathrm{QW}}-1 / \tau+k}\right. \\
& \left.\times\left(1-e^{-\left(1 / \tau_{\mathrm{QW}}-1 / \tau+k\right)}\right)\right],
\end{aligned}
$$

где $\tau_{\mathrm{QW}}-$ время затухания люминесценции КЯ, $\tau-$ время жизни возбужденного состояния $\mathrm{HB}, k-$ константа скорости переноса энергии с КЯ на НВ, $B$ параметр, характеризующий степень возбуждения КЯ в начальный момент времени. Подгоночными параметрами в этой модели являются $\tau_{\mathrm{QW}}, \tau, k, B$. Рисунок 4 показывает, что кинетика затухания люминесценции НВ неудовлетворительно описывается функцией (3).

Такой результат мы трактуем как отсутствие FRET, что, скорее всего, вызвано большим расстоянием между НВ и КЯ. Выше в табл. 2 приведены параметры аппроксимации, соответствующие рис. 4.

Вызывает сомнение полученное в этой модели значение радиационного времени жизни квантовой ямы 100 ns. Мы предполагаем, что, хотя безызлучательный перенос энергии с КЯ на НВ, бесспорно, существует (определяется интегралом перекрытия спектров люминесценции КЯ и поглощения НВ), кинетика затухания люминесценции будет определяться временем жизни излучающего состояния НВ. Как мы определили ранее, времена жизни излучающих состояний КЯ InAsP и НB InAsP близки. В этом случае вклад КЯ в люминесценцию НВ на кинетике люминесценции НВ практически не отразится. Для объяснения значения $\tau_{\mathrm{QW}}=100 \mathrm{~ns}$, полученного с помощью модели (3), можно предположить существование долгоживущих метастабильных состояний, которые описаны, например, в работах $[13,30,31]$. Такие состояния заметно не проявляются на начальных стадиях кинетики люминесценции КЯ, но начинают играть роль в аппроксимации „Хвостов“6 кинетического распределения. 


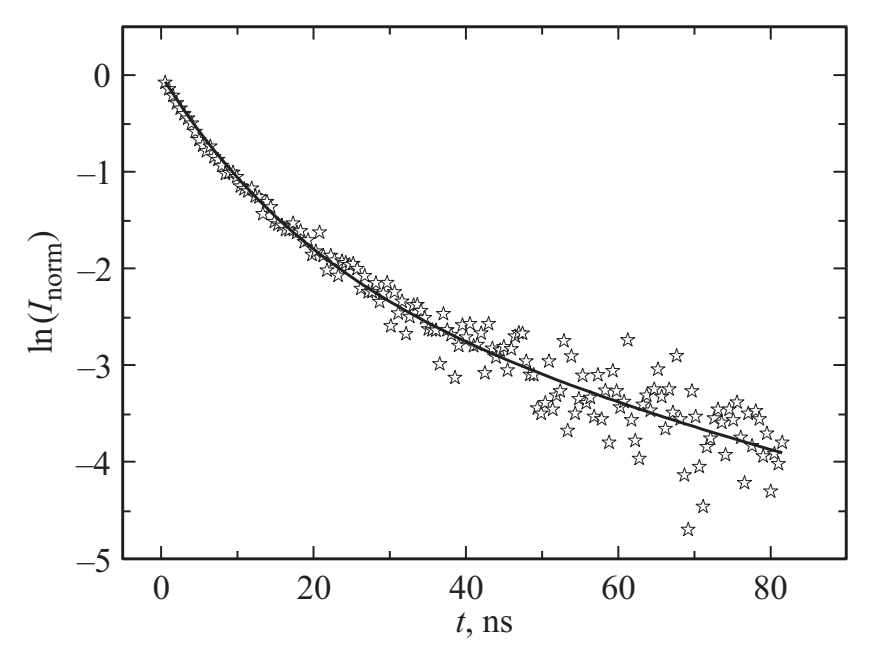

Рис. 5. Нормированная экспериментальная кинетика люминесценции НВ (точки), представленная в логарифмическом виде, и аппроксимация функцией (4) (сплошная кривая) при значениях параметров $\tau=40 \mathrm{~ns}, N_{\mathrm{av}}=2, k=1.9 \mathrm{~ns}^{-1}$.

Kроме FRET, для описания кинетики затухания люминесценции квантовых точек часто используется модель „контактного тушения“ $[15,32]$. В этой модели делаются следующие предположения. Акцепторы энергии (ловушки носителей заряда) располагаются на поверхности квантовых точек (расстояние между донором и акцептором не превышает $1 \mathrm{~nm}$ ). Распределение ловушек на квантовых точках подчиняется распределению Пуассона (подобно распределению молекул на поверхности мицелл [33]). Обратим внимание, что ловушки носителей заряда в полупроводниковых нанокристаллах всегда присутствуют. Они оказывают фундаментальное влияние на релаксацию возбужденных состояний, что делает важным понимание как их природы, так и их роли в фотодинамике всей наноструктуры. Известно, что объёмные структурные деформации на границе раздела кристаллических решёток (в нашем случае InP и InAsP) также являются одной из причин появления ловушек [26,27]. В предлагаемой модели скорость контактного тушения $k$ люминесценции НВ одним акцептором предполагается одинаковой для всех ловушек. Среднее число ловушек около НВ равно $N_{\mathrm{av}} . \tau-$ время излучательной рекомбинации НВ. В этих предположениях функция, описывающая затухание люминесценции по контактному механизму, запишется в виде

$$
I_{\text {norm }}(t)=\exp \left(-\frac{t}{\tau}-N_{\text {av }}\left(1-\exp \left(-k \frac{t}{\tau}\right)\right)\right) .
$$

Подгоночными параметрами здесь являются $\tau, k$ и $N_{\text {av }}$.

На рис. 5 видно, что кинетика затухания люминесценции НВ хорошо описывается моделью „контактного тушения“ (функцией (4)). Отметим, что время $\tau$ практически совпадает с рассчитанным по модели (2). Поскольку функция (4) хорошо аппроксимирует экспериментальные кинетики, нет необходимости учитывать обратный возврат возбуждения с ловушек на НВ. Ясно, что скорость процесса возврата мала, и его учёт выходит за рамки точности эксперимента.

Таким образом, мы полагаем, что „контактное тушение“ является доминирующим механизмом в кинетике релаксации возбужденного состояния НВ. Другими словами, существующие дефекты на границе раздела $\mathrm{HB}$ и массива InP служат основной причиной тушения люминесценции НВ.

\section{Выводы}

На примере синтезированной структуры, состоящей из ННК InP c HB InAsP, показана эффективность параллельной обработки спектрокинетических зависимостей функциями разного вида. Для конкретной исследованной структуры сделана оценка естественного времени жизни люминесценции HB InAsP, составляющем около $10 \mathrm{~ns}$. Обсуждены роль КЯ (сходного с НВ химического состава) и массива ННК InP в заселении возбужденного состояния $\mathrm{HB}$, а также возможные механизмы тушения люминесценции НВ. Проведенный анализ кинетики затухания люминесценции позволил сделать вывод, что кинетика затухания НВ лучше всего описывается в рамках модели контактного тушения, и оценить полную длительность распада возбужденного состояния (его радиационное время жизни) величиной порядка $40 \mathrm{~ns}$. Высказаны предположения о причинах необычно большой длительности переноса возбуждения от InP к HB.

\section{Финансирование работы}

Работа выполнялась при поддержке Министерства науки и высшего образования Российской Федерации (в рамках выполнения госзадания № 16.9791.2017/8.9). Эксперименты по выращиванию образцов были выполнены при поддержке гранта РНФ 19-72-30010.

\section{Конфликт интересов}

Авторы заявляют, что у них нет конфликта интересов.

\section{Список литературы}

[1] LaPierre R.R., Chia A.C.E., Gibson S.J., Haapamaki C.M., Boulanger J., Yee R., Kuyanov P., Zhang J., Tajik N., Jewell N., Rahman K.M.A. // Phys. Stat. Sol. (RRL). 2013. V. 7. N 10. P. 815.

[2] Yan R., Gargas D., Yang P. // Nature Photonics. 2009. V. 3. P. 569.

[3] Zhang Y., Wu J., Aaegesen M., Liu H. // J. Phys. D: Appl. Phys. 2015. V. 48. P. 463001.

[4] Patolsky F., Zheng G., Lieber C.M. // Nanomedicine. 2006. V. 1. N 1. P. 51. 
[5] Цырлин Г.Э., Штром И.В., Резник Р.Р., Самсоненко Ю.Б., Хребтов А.И., Буравлев А.Д., Сочников И.П. // ФТП. 2016. T. 50. B. 11. C. 1441; Cirlin G.E., Shtrom I.V., Reznik R.R., Samsonenko Y.B., Khrebtov A.I., Bouravleuv A.D., Soshnikov I.P. // Semiconductors. 2016. V. 50. N 11. P. 1421.

[6] Kuyanov P., LaPierre R.R. // Nanotechnology. 2015. V. 26. P. 315202.

[7] Хребтов А.И., Резник Р.Р., Убыйвовк Е.В., Литвин А.П., Скурлов И.Д., Парбёнов П.С., Кулагина А.С., Данилов В.В., Цырлин Г.Э. // ФТП. 2019. Т. 53. № 9. С. 1289; Khrebtov A.I., Reznik R.R., Ubyivovk E.V., Litvin A.P., Skurlov I.D., Parfenov P.S., Kulagina A.S., Danilov V.V., Cirlin G.E. // Semiconductors. 2019. V. 53. N 9. P. 1258.

[8] Reimer M.E., Bulgarini G., Akopian N., Hocevar M., Bavinck M.B., Verheijen M.A., Bakkers E.P.A.M., Kouwenhoven L.P., Zwiller V. // Nature Commun. 2012. V. 3. N 737. doi 10.1038/ncomms 1746

[9] Pietryga J.M., Park Y-S., Lim J., Fidler A.F., Bae W.K., Browelli S., Klimov V.I. // Chem. Rev. 2016. V. 116. P. 10513.

[10] Данилов В.В., Панфутова А.С., Ермолаева Г.М., Хребтов А.И., Шилов В.Б. // Опт. и спектр. 2013. Т. 114. № 6. C. 967; Danilov V.V., Panfutova A.S., Ermolaeva G.M., Khrebtov A.I., Shilov V.B. // Opt. Spectrosc. 2013. V. 114. N 6. P. 880.

[11] Spirkoska D., Abstreiter G., Fontcuberta i Morral A. // Nanotechnology. 2008. V. 19. P. 435704.

[12] Смирнов М.С., Овчинников О.В., Перепелица А.С. // Опт. и спектр. 2019. Т. 126. № 1. С. 69; Smirnov M.S., Ovchinnikov O.V., Perepelitsa A.S. // Opt. Spectrosc. 2019. V. 126. N 1. P. 62.

[13] Bodunov E.N., Simões Gamboa A.L. // J. Phys. Chem. C. 2019. V. 123. N 41. P. 25515. doi 10.1021/acs.jpcc.9b07619

[14] Bodunov E.N., Danilov V.V., Panfutova A.S., Simões Gamboa A.L. // Ann. Phys. (Berlin). 2016. V. 528. N 3-4. P. 272. doi 10.1002/andp.201500350

[15] Bodunov E.N., Antonov Y.A., Simões Gamboa A.L. // J. Chem. Phys. 2017. V. 146. P. 114102. doi 10.1063/1.4978396

[16] Brus L. // Phys. Rev. B. 1996. V. 53. N 8. P. 4649.

[17] Chen S., Yoshita M., Ishikawa A., Mochizuki T., Maruyama S., Akiyama H., Hayamizu Y., Pfeiffer L.N., West K.W. // Sci. Rep. 2013. V. 3. N 1941. doi 10.1038/srep01941

[18] Krauss T.D., Peterson J.J. // Nature Mater. 2012. V. 11. P. 14.

[19] de Mello Donegá C., Bode M., Meijerink A. // Phys. Rev. B. 2006. V. 74. P. 085320.

[20] Berberan-Santos M.N., Bodunov E.N., Valeur B. // Chem. Phys. 2005. V. 315. N 1-2. P. 171. doi 10.1016/j.chemphys.2005.04.006

[21] Bodunov E.N., Berberan-Santos M.N., Martinho J.M.G. // Chem. Phys. 2005. V. 316. N 1-3. P. 217. doi 10.1016/j.chemphys.2005.05.020

[22] Berberan-Santos M.N., Бодунов E.H., Martinho J.M.G. // Опт. и спектр. 2005. Т. 99. № 6. С. 955; BerberanSantos M.N., Bodunov E.N., Martinho J.M.G. // Opt. Spectrosc. 2005. V. 99. N 6. P. 918. doi 10.1134/1.2149416

[23] Park Y.-S., Malko A.V., Vela J., Chen Y., Ghosh Y., GarcıaSantamaria F., Hollingsworth J.A., Klimov V.I., Htoon H. // Phys. Rev. Lett. 2011. V. 106. P. 187401.

[24] Bulgarini G., Reimer M.E., Zehender T., Hocevar M., Bakkers E., Kouwenhoven L.P., Zwiller V. // Appl. Phys. Lett. 2012. V. 100. P. 121106.

[25] Asryan L.V., Luryi S. // IEEE J. Quant. Electron. 2001. V. 37. P. 905.
[26] Pal B., Goto K., Ikezawa M., Masumoto Y., Mohan P., Motohisa J., Fukui T. // Appl. Phys. Lett. 2008. V. 93. P. 073105.

[27] Талалаев В.Г., Сеничев А.В., Новиков Б.В., Тотm J.W., Elsaesser T., Захаров Н.Д., Самсоненко Ю.Б., Цырлин Г.Э. // ФТП. 2010. Т. 44. № 8. С. 1084; Talalaev V.G., Senichev A.V., Novikov B.V., Tomm J.W., Elsaesser T., Zakharov N.D., Werner P., Gösele U., Samsonenko Y.B., Cirlin G.E. // Semiconductors. 2010. T. 44. N 8. C. 1050.

[28] Дирак П.А.М. Принципы квантовой механики. М.: Наука, 1979. 480 c.; Dirac P.A.M. The Principles of Quantum Mechanics. Oxford University Press, 1930. 257 p.

[29] Ермолаев В.Л., Бодунов Е.Н., Свешникова Е.Б., Шахвердов T.A. Безызлучательный перенос энергии электронного возбуждения. Л.: Наука, 1977. 312 с.; Ermolaev V.L., Bodunov E.N., Sveshnikova E.B., Shakhverdov T.A. Nonradiative Transfer of Electronic Excitation Energy. Leningrad: Nauka, 1977. $312 \mathrm{p}$.

[30] Bodunov E.N., Simões Gamboa A.L. // J. Phys. Chem. C. 2018. V. 122. N 19. P. 10637. doi 10.1021/acs.jpcc.8b02779

[31] Bodunov E.N., Simões Gamboa A.L. // Semiconductors. 2019. V. 53. N 16. P.89; doi 10.1134/510637826119120078

[32] Bodunov E.N., Simões Gamboa A.L. // Semiconductors. 2018. V. 52. N 5. P. 587. doi $10.1134 / \mathrm{S} 1063782618050044$

[33] Bodunov E.N., Berberan-Santos M.N., Martinho J.M.G. // Chem. Phys. Lett. 1998. V. 297. N 5-6. P. 419. doi $10.1016 /$ S0009-2614(98)01151-8 